ББК 63.4

$$
\begin{gathered}
\text { Организация конференции и издание материалов проведены } \\
\text { при финансовой поддержке Российского фонда фундаментальных исследований, } \\
\text { проект № 19-09-20008 }
\end{gathered}
$$

Утверждено к печати Ученым советом ИИМК РАН

Редакционная коллегия тома II: А. В. Поляков, Е. С. Ткач (отв. редакторы), М. Т. Кашуба, Л. Б. Кирчо, Е. А. Черлёнок, В. Я. Стёганцева, А. И. Климушина

Рещензенты: д. и. н. Л. Б. Вишняцкий, д. и. н. А. А. Выборнов

Программный комитет конференции: академик РАН, д. и. н., проф. М. Б. Пиотровский (Государственный Эрмитаж, почетный председатель); д. и. н. В. А. Лапшин (ИИМК РАН, председатель); д. и. н. А. В. Головнёв (МАЭ РАН, сопредседатель); д. и. н. В. А. Дергачёв (Высшая антропологическая школа, Молдова, сопредседатель); д. и. н. И. Ф. Попова (ИВР РАН, сопредседатель); академик АН Республики Узбекистан, д. и. н., проф. Э. В. Ртвеладзе (сопредседатель); к. и. н. А. В. Поляков (ИИМК РАН, зам. председателя); к. и. н. В. А. Алёкшин (ИИМК РАН, зам. председателя); д. и. н. Ю. Е. Берёзкин (МАЭ РАН); Dr., Prof. Н. Бороффка

(Германский археологический институт, Германия); В. С. Бочкарёв (ИИМК РАН);

Dr. Э. Кайзер (Свободный университет Берлина, Германия); к. и. н. М. Т. Кашуба (ИИМК РАН); д. и. н. Л. Б. Кирчо (ИИМК РАН); к. и. н. А. В. Кияшко (Южный федеральный университет); к. и. н. П. Ф. Кузнецов (СГСПУ); к. и. н. Н. М. Малов (СНИГУ); к. и. н. В. П. Никоноров (ИИМК РАН); Ю. Ю. Пиотровский (Государственный Эрмитаж); д. и. н., проф. Д. Г. Савинов (Институт истории СПбГУ); к. и. н. В. Н. Седых (Институт истории СПбГУ); к. и. н. Н. Н. Скакун (ИИМК РАН); к. и. н. Н. Ф. Соловьёва (ИИМК РАН); к. и. н. А. И. Торгоев (Государственный Эрмитаж); к. и. н. Е. А. Черлёнок (Институт истории СПбГУ)

Организационный комитет конференции: к. и. н. А. В. Поляков (ИИМК РАН, председатель); к. и. н. В. А. Алёкшин (ИИМК РАН, зам. председателя); В. С. Бочкарёв (ИИМК РАН); к. и. н. М. Т. Кашуба (ИИМК РАН); д. и. н. Л. Б. Кирчо (ИИМК РАН);

А. И. Климушина (ИИМК РАН, отв. секретарь); к. и. н. В. П. Никоноров (ИИМК РАН); Ю. Ю. Пиотровский (Государственный Эрмитаж); В. Я. Стеганцева (ИИМК РАН); В. В. Терёхина (ИИМК РАН, МАЭ РАН, отв. секретарь); к. и. н. Е. С. Ткач (ИИМК РАН); И. Ж. Тутаева (Государственный Эрмитаж); к. и. н. Е. А. Черлёнок (Институт истории СПбГУ)

Древности Восточной Европы, Центральной Азии и Южной Сибири в контексте связей и взаимодействий в евразийском культурном пространстве (новые данные и концепции): Материалы Международной конференции, 18-22 ноября 2019 г., Санкт-Петербург. Т. ІІ. Связи, контакты и взаимодействия древних культур Северной Евразии и цивилизаций Востока в эпоху палеометалла (IV-I тыс. до н. э.). К 80-летию со дня рождения выдающегося археолога В. С. Бочкарёва. - СПб.: ИИМК РАН, Невская Типография, 2019. - 287 с.

ISBN 978-5-907053-35-9

DOI 10.31600/978-5-907053-35-9 
Рындина Н. В. 1998. Древнейшее металлообрабатывающее производство Юго-Восточной Европы. М.

Черных Е. Н. 1966. История древнейшей металлургии Восточной Европы. М.

\title{
THE ROLE OF CULTURAL TIES IN THE FORMATION AND DEVELOPMENT OF METALLURGICAL PRODUCTION OF YAMNAYA CULTURE IN THE SOUTH URALS
}

\section{Nina L. Morgunova}

Orenburg State Pedagogical University, Orenburg, Russia

Keywords: metal production, Eneolithic, Early Bronze Age, Samara culture, Pit-Grave (Yamnaya) culture, southern Ural region.

The first acquaintance of the people of the South Ural region with metal production took place in the Eneolithic Age under the influence of contacts with the population of the Northern Black Sea littoral. At sites of the Samara and Khvalynsk cultures (5000-4500 BC), the copper artifacts known are of Balkan origin. The first Ural center of metal production arose on the base of the Kargaly ore deposit in 3700-3600 cal BC and was related with the early stage of the Pit-Grave culture. Traces of metal production have been noted in the layer of the Early Bronze Age at the Turganik Settlement situated $70 \mathrm{~km}$ to the west from Kargaly. Metal objects come from kurgans of all the three stages of the Pit-Grave culture, however most of them were found in burials of the advanced stage (3200-2600 cal BC). In burials of the Repin stage, the range of objects is rather small: knives and awls. Assemblages of metal artifacts of the advanced stage are characterized by the increase of the number of finds in a single burial, volume of metal in some objects and functional diversity (Fig. 1).

\section{ВЕКТОРЫ КУЛЬТУРОГЕНЕЗА И ПРОБЛЕМА СТАНОВЛЕНИЯ СРУБНОЙ КУЛЬТУРЫ НА СЕВЕРЕ НИЖНЕГО ПОВОЛЖЬЯ}

\author{
В. А. Лопатин \\ Саратовский государственный университет им. Н. Г. Чернышевского, \\ Саратов, Россия
}

DOI: 10.31600/978-5-907053-35-9-23-25

Ключевые слова: средний и поздний бронзовый век, культурогенез, срубная культура, Бабино, Лола, Вольск, покровская культура, Синташта, Петровка.

Разнообразие культур позднего бронзового века степной Евразии объективно отражает многокомпонентный характер культурогенеза, в котором определяющими факторами были пространство, время и культурно-историческое развитие древних иранцев.

Пространство, ландшафт, природно-географическая среда имеют огромное значение в динамике культурных моделей и хозяйственных систем. В геополитическом отношении степное Волго-Уралье всегда оставалось привлекательным, а протекавшие здесь культурные, этнические и политические процессы нередко формировали судьбоносные направления мировой истории. Региональные условия определяли особую специфику этногенетических явлений (дискретность, нестабильность и мозаичность), крайне напряженные или острокритические варианты полиэтничной энтропии - глобальные миграции, ассимиляции, межкультурные миксации. Волго-Уралье в древности - всегда «спорная территория», как любой район степи между Чёрным морем и Саяно-Алтаем (Лопатин 2005: 8). Монотонные ландшафты и крайне напряженные в своей экстенсивности варианты скотоводства формировали здесь ярко выраженные персистентные типы первобытных социумов (Лопатин 2006: 5). 
Середина II тыс. до н. э. должна рассматриваться как переходный период, в течение которого происходили качественные трансформации культурных компонентов, вовлеченных в интеграционные процессы. Важно синергетическое понимание этого отрезка времени как пункта бифуркации, в котором складываются срубная и алакульская мегакультуры. Для нас наиболее важен период взаимодействия культурных групп посткатакомбного, постшнурового и постабашевского типов (Кривая Лука, Бабино, Лола, Воронеж, Вольск, Лбище), а также роста доминантности активаторов культурогенеза (Синташта, Потапово, Петровка, Покровск). В пределах этого периода также необходимо рассмотреть формирующиеся локальные варианты новых культур.

Культурогенез понимается как множественные векторные процессы, в ходе которых наблюдаются рост, критические пики, спады, плавное развитие. В глобальных масштабах культурно-генетические процессы могут приобретать как дискретный, так и линейный характер. Эти интервалы по-своему совпадают с дивергентными и конвергентными явлениями в развитии первобытных культур, что является выражением диалектической сущности культурогенеза.

Векторы культурогенеза - это условные направления динамики взаимодействующих культурных компонентов, результатами которой становятся локальные варианты будущих культур. Выявление процессов взаимодействия и специфических особенностей формирующихся вариантов - одна из ключевых задач исследования. Данная позиция не противоречит концепциям «очагов» культурогенеза, которые основаны на выделении блоков «материнских» культур и активаторов динамики, констатируемых в качестве исходных культурно-исторических явлений (Бочкарёв 1991; 1995). Эти яркие феномены активизации мы рассматриваем как очень значимые фрагменты - фазы подъема, нарастающей динамики глобальных, перманентно развивающихся культурно-генетических процессов. Под активизацией культурных компонентов понимается конкретное движение (миграции) носителей определенных культур из первичных областей на территорию Нижнего Поволжья, Волго-Донского междуречья и степного Волго-Уралья. Однако в этих процессах также важно учитывать опосредованные трансляции культурных элементов, явления непрямых аккультураций и активного обмена традициями.

Памятники покровского типа - доминирующий и консолидирующий компонент, имеющий ключевое значение в пиковой фазе культурогенеза и социогенеза на переходном этапе и в начале позднего бронзового века (Малов 2003: 157). Как одно из явлений блока «колесничных» культур, покровский феномен - несомненный активатор культурогенеза, наиболее эффективно проявивший себя в Волго-Уральском регионе (Лопатин 2010).

\section{Литература}

Бочкарёв В. С. 1991. Волго-Уральский очаг культурогенеза эпохи поздней бронзы // Массон В. М. (отв. ред.). Социогенез и культурогенез в историческом аспекте: Мат-лы методологического семинара ИИМК АН СССР. СПб. С. 24-27.

Бочкарёв В. С. 1995. Карпато-Дунайский и Волго-Уральский очаги культурогенеза эпохи бронзы (опыт сравнительной характеристики) // Бочкарёв В. С. (отв. ред.). Конвергенция и дивергенция в развитии культур эпохи энеолита - бронзы Средней и Восточной Европы: Материалы конф. 21-25 августа 1995 года, Саратов. Ч. І СПб. С. 18-29 (АИ. Вып. 25/I).

Лопатин В. А. 2005. Этногенезы в Нижнем Поволжье (иранский фрагмент) // Малов Н. М. (отв. ред.). Народы Саратовского Поволжья. История и современность: МОНПК, Саратов, 28-29 октября 2004 г.. Саратов. С. 8-10.

Лопатин В. А. 2006. Евразийский феномен имперского пространства (фактор ландшафта) // Малов Н. М. (ред.). Народы Саратовского Поволжья. История, этнография и современность: 
МОНПК, 15 декабря 2005 года, Саратов. С. 5 (Тр. Саратовского обл. музея краеведения. Вып. 6).

Лопатин В. А. 2010. Векторы культурогенеза (к проблеме становления срубной культуры на севере Нижнего Поволжья в середине II тыс. до н. э.) // Известия СГУ. Новая серия. Серия история, международные отношения. Т. 10. Вып. 2. Саратов. С. 41-45.

Малов Н. М. 2003. Погребения покровской культуры с наконечниками копий из Саратовского Поволжья // Археологическое наследие Саратовского края. Охрана и исследования в 2001 году. Саратов. Вып. 5. С. 157-219.

\title{
VECTORS OF CULTUROGENESIS AND THE PROBLEM OF THE FORMATION OF TIMBER-GRAVE CULTURES IN THE NORTHERN REGION OF THE LOWER VOLGA
}

Vladimir A. Lopatin

Saratov State University, Saratov, Russia

Keywords: culturogenesis, Timber-Grave culture, Babino, Lola, Volsk, Pokrovsk, Sintashta, Petrovka. In the $2^{\text {nd }}$ millennium $\mathrm{BC}$, the cultural genesis was of a complicated and multi-component character. The early variants of the Timber-Grave (Srubnaya) culture developed differently in different natural geographic niches of the Volga, Don and Ural with participation of diverse transitional cultural types at the turn between the Middle and Late Bronze Age. In the following periods, we can see a global convergence of steppe animal-breeding tribes and the general leveling of the local peculiarities of the Timber-Grave culture.

\section{ВОДНЫЙ ТРАНСПОРТ В БРОНЗОВОМ ВЕКЕ РУССКОЙ РАВНИНЫ}

\author{
Е. А. Кашина, Е. И. Гак
}

Государственньй исторический музей, Москва, Россия

DOI: 10.31600/978-5-907053-35-9-25-27

Ключевые слова: водный транспорт, долбленая лодка, берестянка, Восточная Европа, лесная зона, бронзовый век, радиоуглеродное датирование.

Согласно имеющимся данным на территории лесной зоны Русской равнины в бронзовом веке могли сосуществовать как минимум два вида водного транспорта - долбленые и каркасные лодки. Долбленые лодки из археологических памятников и случайных находок в Западной Европе, возраст которых определен радиоуглеродным методом, датируются от 7500 ВС и позже (Arnold 1995; Lanting 2000). Образцы деревянных весел известны как в Западной, так и в Восточной Европе (Hartz, Lübke 2000; Burov 1996; Кашина, Чаиркина 2017). К сожалению, морфологические характеристики весел не могут являться базой для интерпретации их функционального назначения применительно к конкретным типам лодок, поскольку весла во все времена делались по ростовым меркам пользователя. Древнейшие находки долбленых лодок в Восточной Европе, датирующиеся около 3000 ВС, происходят из торфяниковых стоянок в лагунах Латвии и Литвы (Ванкина 1970; Piličiauskas 2016). Использование каркасных лодок-берестянок предполагается умозрительно, на основании свидетельств существования развитых навыков работы с берестой и смолистыми веществами. Речь идет о технологии вклейки кремневых вкладышей в костяную обойму при изготовлении предметов метательного вооружения, а также о берестяных изделиях на торфяниковых стоянках. Никаких деревянных 